\title{
The tactile triangle: a design research framework demonstrated through tactile comparisons of textile materials
}

\author{
Douglas Atkinson* \\ London College of Fashion, \\ 20 John Prince's Street, London, W1G 0BJ, UK \\ Email: d.atkinson@fashion.arts.ac.uk \\ *Corresponding author
}

\section{Sharon Baurley and Bruna Beatriz Petreca}

The Royal College of Art,

Kensington Gore, London, SW7 2EU, UK

Email: sharon.baurley@rca.ac.uk

Email: bruna.petreca@network.rca.ac.uk

\section{Nadia Bianchi-Berthouze}

UCLIC,

University College London,

Gower Street, London, WC1E 6BT, UK

Email: n.berthouze@ucl.ac.uk

\section{Penelope Watkins}

FITU Ltd. Gayton, Kings Lynn, PE32 1QS, UK

Email: penelopewatkins@aol.com

\begin{abstract}
Tactile experiences of textile materials are difficult to communicate and elicit. To interrogate this space we propose the tactile triangle, a framework to facilitate systematic analysis and comparison of tactile experiences. The three levels reflect different aspects of tactile experience and possible methods to capture them: physical properties, in which human senses or objective testing measure fabric properties; the perceptual space level in which triadic comparisons reveal combinations of various dimensions which capture and describe tactile experiences; and finally the communication level, in which design games elicit languages communicating tactile perceptions. A case study illustrates the framework's use to compare the tactile experiences of textiles in experts and consumers. The results show expert and consumer perceptions overlapped and correlated well to objective measures except in the perception of temperature. We conclude by discussing the framework's effectiveness, the contribution of individual methods, and its potential as a communication tool for designers.
\end{abstract}

Keywords: textile; fabric; sensory; touch; perception; aesthetics. 
Reference to this paper should be made as follows: Atkinson, D., Baurley, S. Petreca, B.B., Bianchi-Berthouze, N. and Watkins, P. (xxxx) 'The tactile triangle: a design research framework demonstrated through tactile comparisons of textile materials', J. Design Research, Vol. X, No. Y, pp.000-000.

Biographical notes: Douglas Atkinson is a Research Fellow at The Digital Anthropology Lab, London College of Fashion. His work explores how the digital can be used to infer and represent sensory and emotional aspects of human experience, which are crucial to our identities, relationships to fashion items and the experience of fashion makers. In parallel, he investigates the changes in contemporary design practice due to increasing detachment from material experience. He has previously conducted RCUK, ESRC and EPSRC funded research at London College of Fashion, Central Saint Martins College of Art and Design and Brunel University.

Sharon Baurley is Head of Programme - Design Products at the Royal College of Art. She was formerly Head of Design in the School of Engineering and Design, Brunel University. She has conducted Doctoral and Post-Doctoral research at the Royal College of Art, Musashino Art University, Tokyo, and John Moores University, Liverpool. She has collaborated on research with Vodafone, HP Labs, and Horizon: an RCUK funded Digital Economy Research Hub. She has received numerous national and international design awards including the Josef Otten Award for Technical Innovation and the Ideacomo Award for Printing and Dyeing from the Japanese Fashion Foundation.

Bruna Beatriz Petreca is a researcher in Fashion and Textiles BA from University of São Paulo-USP. While working in research with textiles in a technology research institute in Brazil, she gained experience in $R \& D$ projects, quality control and manufacture of textiles and apparel. Recently, the collaboration with the project 'Digital Sensoria: design through digital perceptual experience', as a Visiting Fellow to London College of Fashion, unfolded in her current $\mathrm{PhD}$ research at The Royal College of Art. Her work occasionally includes collaborations, resulting in the design of costumes and fashion editorials.

Nadia Bianchi-Berthouze is a Professor in Affective Computing and Interaction at UCL Interaction Centre (UCLIC). The premise of her research is that affect, emotion, and subjective experience should be factored into the design of interactive technology. Indeed, for technology to be truly effective in our social network, it should be able to adapt to the affective needs of each user group or even each individual. The aim of her research is to create systems/software that can sense the affective state of their users and use that information to tailor the interaction process.

Penelope Watkins undertakes research and development in all the aspects of clothing design and production, particularly fashion products designed for individual body shape. She was formerly part of the Fashion Science Research group funded by the EPSRC/AHRC Designing for the 21st century scheme, in collaboration with the Cambridge Engineering Design Centre. She has received the DfES UK/Hong Kong Fellowships for Excellence, and a Research Fellowship in The Department of Automated and Mechanical Engineering at The Chinese University Hong Kong. She has also collaborated with University of East London to develop Fabric Formworks, 3D fabric structures for concrete and earth construction. 


\section{Introduction}

Tactile experiences reveal a very rich and complex territory, which has been little described by research. The intricacy of this experience derives from touching being an inherently interactive experience (Sonneveld and Schifferstein, 2008); touch and being touched are equally important for its unfolding. Much of this experience remains unarticulated or even unconscious, which reflects on the difficulty people have to talk about how textile materials feel, likewise about how they feel when engaging with textiles. Hence, the tactile experience is formed by psychophysical and affective responses, which can be elicited and measured by diverse methods (e.g., triadic experiments or rating against sensory scales), as well as by the physicality of the materials, which can be objectively measured (Chen et al., 2009). Given a physical encounter with a material, stimulation of the tactile receptors in the skin will proceed, as has been previously described by research (Lederman and Klatzky, 2009). These will be processed in the brain, firstly in the psychophysical level (sensorial judgements), which will incur in classifying materials, to then combine and compare these judgements, based on memories that will result in affective judgements (Chen et al., 2009).

Literature in the textile realm highlights a number of methods, both subjective (Winakor et al., 1980; Philippe et al., 2003; Sular and Okur, 2008; Soufflet et al., 2004) and objective (Kawabata, 1982; Lai et al., 2002; Ly et al., 1991; Minazio, 1995; De Boos, 2005), used in research and industry to predict or discern the tactile properties of textiles. During their education, and through experience in industry, fashion and textile designers are trained to perceive differences in the tactile qualities of textiles. To our knowledge there is only one piece of research (Soufflet et al., 2004) into the abilities of un-trained consumers to discern such differences, in which the evaluations of experts and non-experts showed no distinction on the perceptual level, whereas experts differ from non-experts in terms of verbalising their perceptions and can identify more dimensions.

In this paper, we propose The Tactile Triangle framework to facilitate the analysis of tactile experiences and their comparison by building on the literature on approaches to the analysis of subjective experience. To demonstrate the application of the framework a case study compares expert designers' subjective perceptions, non-expert consumers' subjective perceptions and objective testing of textiles. In doing so we also contribute to answering the important and still open question of whether both expert and consumer perceptions correlate with objective measurements of the tactile properties of textiles and relate to each other. The design, execution and results for each approach are laid out consecutively to aid understanding and correlation of results is outlined in Section 6.

Figure 1 shows the current landscape of research into tactile perceptions of textiles. The link between designers and mechanised testing is well established, and previous research reveals one study linking the perceptions of designer and consumer, and no research into the link between consumer perceptions and mechanised testing. 
Figure 1 The landscape of current research into tactile experience of textiles

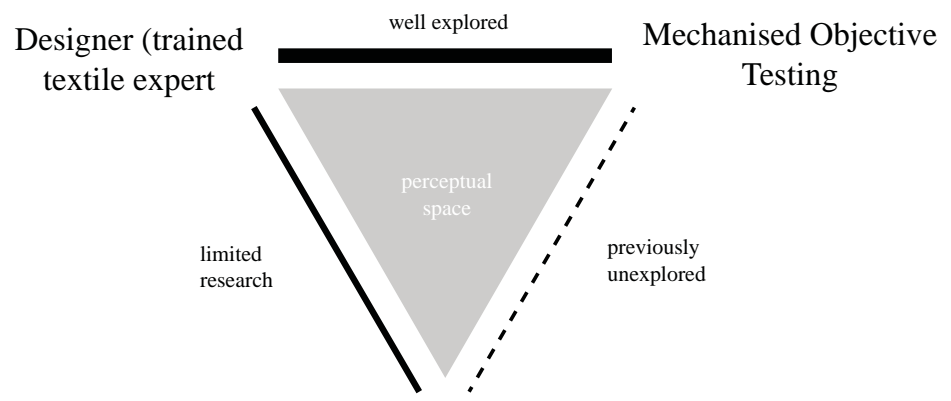

Consumer

(un-trained, non-expert)

There has been much recent interest in supporting designers to make informed choices (van Kesteren, 2008; Sonneveld and Schifferstein, 2008; Karana, 2009; Karana et al., 2009; Lee et al., 2010), our framework will significantly add value to their creative output, aiding them in 'understanding other peoples understanding' (Krippendorff and Butler, 2008) of tactile properties or 'hand feel' (the sensory tactile qualities of fabric against the skin) of textile materials. This is particularly important when using collaborative design processes where communication of such perceptions is difficult.

We begin this paper by discussing the available literature relating to tactile evaluation of textiles (Section 1). This is then used to propose the framework and to inform the selection of a set of bi-polar descriptive scales (communication level) and a set of textile samples by textile experts for use in the studies that comprise our framework (Section 2). The tactile properties of our chosen textile samples are tested using objective testing (Section 3) and evaluated by un-trained consumers in both an informal design gaming process (Section 4) and a structured Triadic Comparison process (Section 5). The results of these evaluations are then compared and contrasted (Section 6), limitations are considered (Section 7) and conclusions and future work are discussed (Sections 8 and 9).

\section{Literature review}

In this paper, the literature review is confined within the tactile sensory perception of textile materials.

\subsection{Textile hand evaluation methods}

A literature review was undertaken to determine a taxonomy commonly used in the textiles and clothing industries to measure and describe subjective textile hand. Subjective textile hand refers to the non-mechanised sensory experience. As defined by Philippe et al. (2003) "This is the reaction of the sense of touch, when fabrics are held in the hand. (...) "hand" can be considered as a meta-concept that takes into account not only the sensory aspect but also aspects such as formability, aesthetics, drapability and tailorability". 
In contrast, objective textile hand mechanically measures tactile qualities of textiles, usually obtained by testing with one of two systems. The Kawabata Evaluation System (KES-F) and the SiroFAST (Fabric Assurance by Simple Testing) system (Kawabata, 1982; Lai et al., 2002; Ly et al., 1991; Minazio, 1995; De Boos, 2005) have been used in industry for predicting the aesthetic qualities perceived by human touch and communicating them both in manufacture and in quality assurance processes. For such purpose, much investigation has taken place to compare the results of Subjective and Objective textile testing (Howorth and Oliver, 1958; El-Mogahzy et al., 2005). Crucially, only one study (Soufflet et al., 2004) attempts to understand the relationship between consumer perceptions of textiles and mechanised objective testing. Recently developed and yet to be evaluated are the SDL Atlas Fabric Touch Tester and the PhabrOmeter.

Experimental procedures utilised for textile hand evaluation in the literature are highly disparate. For the purposes of this study, we draw on those that included visibility of the textiles (Picard et al., 2003; Philippe et al., 2003; Soufflet et al., 2004), un-trained consumers (Winakor et al., 1980; Laughlin, 1991; Kim and Winakor, 1996; Hung and Chuang, 1999; Picard et al., 2003; Nogueira et al., 2009), trained panels and textile experts (Moody et al., 2001; Philippe et al., 2003; Soufflet et al., 2004; Valatkiene and Strazdiene, 2006; Sular and Okur, 2008), types of rating including bi-polar (Winakor et al., 1980; Hung and Chuang, 1999; Philippe et al., 2003; Sular and Okur, 2008; Soufflet et al., 2004) or grouping and difference [e.g., Triadic Comparison or Free Sorting (Laughlin, 1991; Moody et al., 2001; Philippe et al., 2003; Picard et al., 2003; Soufflet et al., 2004)], samples of differing specifications and handling gestures (Winakor et al., 1980; Picard et al., 2003; AATCC Evaluation Procedure 5, 2006; Valatkiene and Strazdiene, 2006; Sular and Okur, 2008).

Procedures regarding objective textile testing in literature were found to be confusing, and only Sular and Okur (2008) carried out full objective testing of their samples. Cardello et al. (2003) assert “(...) studies of human responses to clothing materials suffered from a lack of theoretical models to guide research in the field. As a result, the field was plagued by idiosyncratic and undefined terminology, a lack of operational constructs, confusion over the kinds of panellists to use, failure to adopt modern psychophysical techniques, and general confusion in communication about fabric attributes and qualities”. The continued inconsistency in approaches is surprising given that there is a published AATCC (2006) standard 'Fabric Hand: Guidelines for the Subjective Evaluation' which sets out parameters for just such experiments. As the issues cited by Cardello et al. (2003) are still currently applicable and the AATCC Evaluation Procedure 5 (2006) guidelines have not been widely adopted by designers or industry for textile evaluation, we chose not to apply the standard to our own testing. We also believe the AATCC Evaluation Procedure 5 (2006) guidelines promote unnatural interactions with textiles and so are incompatible with consumer experience.

\subsection{Review of frequently used subjective textile descriptors}

In reviewing the surrounding literature we looked solely for subjectively obtained descriptors. Although there were a number of papers we tried to focus on research conducted in, or translated into English.

The set of perceptual scales was obtained by removing the hedonic terms, value judgements, similes, names of textile type and structure and descriptors not understood to 
be related to textile hand. This left a sample of 69 descriptors, from which we produced a subset of four bipolar pairs.

\subsection{Design methods}

Touch has always been a difficult sense to communicate (Sonneveld and Schifferstein, 2008), as it is reliant largely on subjective analogy. Increasingly in this digital age it is vital that there exists a tool with which consumers and designers can express their needs or ideas surrounding the tactile meanings of materials. Researchers such as Bang (2009), Brandt et al. (2008), Karana et al. (2009) and Fenko et al. (2010) have made use of collaborative and design influenced processes to probe participants' perceptions of materials; although some studied textiles, none specifically investigated their tactile properties. They have used methods that allow un-trained consumers' tacit knowledge to be mobilised and harnessed by researchers to aid in understanding their tactile perceptions of materials. It is the accuracy and reliability of this tacit knowledge that we wish to investigate.

\section{The tactile triangle framework}

In this study, we propose the 'Tactile Triangle' framework, grounded in the literature on textile perception and elicitation of subjective experiences, identifying three levels that affect tactile experiences of textiles and that need to be analysed to understand tactile experiences. The first is the physical level, i.e., the physical properties of textiles that affect their perception. The ability to capture these physical properties depends on the sensitivity of the measuring device (e.g., a mechanical device, or the human skin sensors). The second is the perceptual space level that defines the perceptual dimensions (that may not directly match physical properties) that people use to evaluate textiles. Finally, the communication level, i.e., the vocabulary (e.g., words, sentences, gestures) that is available to communicate such experiences.

The framework (Figure 2) was developed through a review of the literature, which attempted to more comprehensively explore the many facets of tactile experience. The three core levels described are believed to be the most significant. The contribution of the framework is to facilitate a more systematic analysis of tactile experience and allow people to communicate that which is traditionally hard to articulate by providing shared points of reference.

At it is core the framework (Figure 2) is comprised of three levels which inform our understanding of the tactile perception being studied: the physical level, relating to the influence of physical properties of the object or material on tactile experience, the communication level which relates to the way people describe and communicate their perceptions of the object or material (e.g., the terms they use to describe it's tactile properties) and finally the perceptual space level which holistically explores the dimensions people use to characterise their tactile experience of the object or material (e.g., which perceptions are most significant in forming a tactile opinion of the object or material and how do they influence one another?). The grey inner ring shows the areas that can be studied at each level and suggests related methods. Finally, the coloured outer rings show influencing factors that may affect the results of studies conducted at each level using the methods indicated in the grey inner ring. 
Figure 2 The tactile triangle framework (see online version for colours)

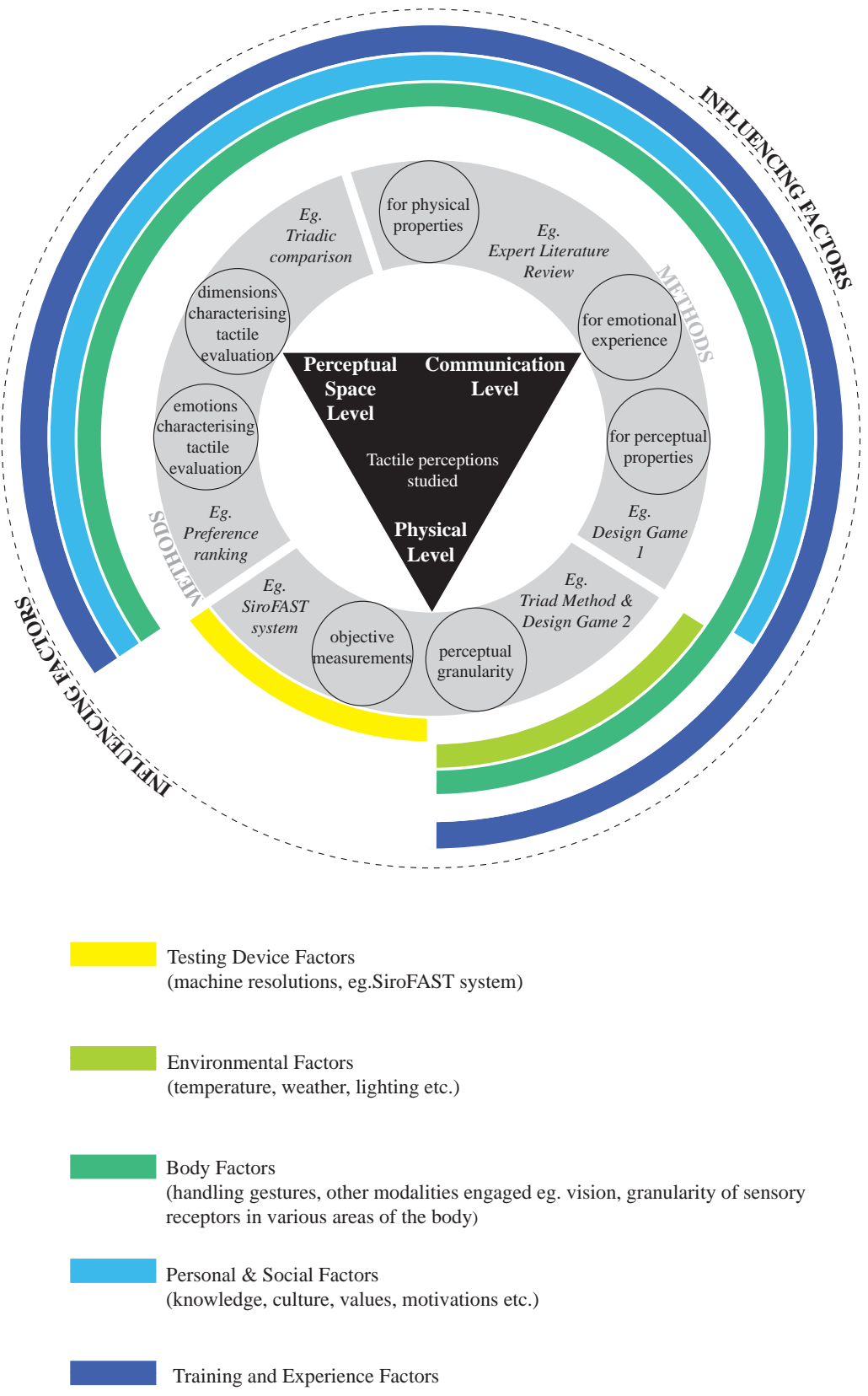


We describe a case study comparing tactile perception of textile experts with consumers, illustrating how our 'Tactile Triangle' framework facilitates the analysis of tactile perceptions and their comparison. For each level, specific methods are proposed to uncover each target group's tactile experiences of a set of textiles: objective testing to measures fabrics directly; triadic comparisons to understand the dimensional spaces used to evaluate tactile perception; design games to elicit the language to communicate tactile perceptions and to investigate each group's ability to detect differences in physical properties.

\subsection{Selection of perceptual scales for case study}

To investigate how the framework can be applied to design research, we use a case study that explores how designers and consumers differ in the perceptual evaluation of textiles, an important question that is currently un-answered by the literature. To choose the perceptual scales, we conducted a literature review that identified four scales as the most relevant properties to be explored. The four bi-polar pairs of terms selected were: rough-smooth, the most common term pairing in the literature review. Thick-thin and warm-cool, jointly the second most common pairings and the fourth most commonly used stiff-flexible. These also according to the literature (Fan et al., 2004; Behery, 2005) relate to objectively measurable properties of fabrics:

- Physical: Thickness, mass per unit area. Relating to thick-thin.

- Mechanical: Extensibility, bending properties, shear. Relating to stiff-flexible.

- Surface: Compression properties, friction, surface irregularity. Relating to rough-smooth.

- Thermal: Conductivity. Relating to warm-cool.

\subsection{Textile materials selection for case study}

In order to compare designers and consumers perceptions on the scales derived from the literature review, an expert panel evaluated textiles to choose a set that reflected the chosen scales (above). As a starting point a set of $100 \%$ cotton textiles were selected, as this fibre comprises 50\% of world fabric consumption (Kooistra et al., 2006). Selection was based on a consensus of subjective hand evaluation by textile experts within the research team to represent a wide variety of diverse tactile experiences. Despite contrary claims by Yenket et al. (2007) a study by Moody et al. (2001) showed that colour impacted on hand evaluation studies. Therefore to minimise potential colour influence only white and un-dyed textiles were used. The textiles were chosen to ensure that participants would not be biased by novelty, as most people have experience of them: 'Jersey', a conventional T-shirt textile (see Figure 4 No. 1). 'Muslin' used in summer dresses and blouses (see Figure 4 No. 2). 'Poplin', a conventional shirting textile used in shirts and blouses (see Figure 4 No. 3). 'Voile', used in lightweight summer shirts, blouses and dresses (see Figure 4 No. 4). 'Heavy Drill', analogous to Denim that is found in jeans and outerwear (see Figure 4 No. 5). 'Raised Cotton' used in nightwear, coats and outerwear (see Figure 4 No. 6) and 'Buckram', a stiffener used in hats and accessories (see Figure 4 No. 7 ). 


\section{Physical level: mechanised objective testing of physical properties of textiles}

Objective testing was carried out to ascertain the physical properties of the cotton textile set. This provides quantitative data on the physical level of tactile experience which can be compared to the qualitative studies of perceptual and communication levels.

\subsection{Objective textile testing methods}

The cotton sample set was evaluated for thermal, surface, physical and mechanical properties. The following definitions apply:

Using a thermal conductivity analyser (Mathis TCi, C-Therm Technologies Ltd.) thermal qualities, related to the warm-cool perceptual scale, were obtained through thermal conductivity (Hu and Yeung, 2006) and effusivity (Pan, 2007) tests.

The SiroFAST System was used to assess thick-thin perceptual scale, representing the difference, given in millimetres, between the average fabric thicknesses when different loads are applied, specifically 9,800 $\mathrm{Pa}$ and $196 \mathrm{~Pa}$.

The stiff-flexible perceptual scale, also measured using the SiroFAST system, is calculated from the relation between the bending length and fabric mass per unit area, and is given in $\mu \mathrm{N}$.m. This pair can also be influenced by mechanical properties such as extension, shear and formability, which were measured using the same system (Minazio, 1995).

We were not able to produce results for rough-smooth as there was no internationally standardised methodology for the roughness assessment of textiles at the time. Despite this, the rough-smooth perceptual scale was one of the most frequently occurring in prior literature and the research team felt it was an important scale for tactile assessment. As Das et al. (2007) state fabric hand “... is undoubtedly influenced by the static and dynamic frictions between the cloth surface and thumb or finger, involving the other properties like flexibility, thickness and shear in the assessment”.

\subsection{Objective textile testing results}

Results for thermal, physical and mechanical tests are presented in Table 2 and discussed below. For the results related to the SiroFAST System, the definitions for the acronyms are given in Table 1, and a chart containing results of the seven fabrics is given in Figure 1.

Table 1 Definitions for the acronyms related to the properties evaluated by the SiroFAST system

\begin{tabular}{lrr}
\hline Acronyms & Evaluated property & Unit \\
\hline $\mathrm{T} 2$ & Fabric thickness at 196Pa load $\left(2 \mathrm{gf} / \mathrm{cm}^{2}\right)$ & $\mathrm{mm}$ \\
$\mathrm{T} 100$ & Fabric thickness at 9800 Pa load $\left(100 \mathrm{gf} / \mathrm{cm}^{2}\right)$ & \\
& Fabric surface thickness. Represents the difference between the & \\
\hline
\end{tabular}


Table 1 Definitions for the acronyms related to the properties evaluated by the SiroFAST system (continued)

\begin{tabular}{lcc}
\hline Acronyms & Evaluated property & Unit \\
\hline ST & Average fabric thickness at 9,800 Pa and the average fabric thickness at & $\mathrm{mm}$ \\
& & $196 \mathrm{~Pa}$ \\
& Released surface thickness. Represents the difference between the \\
STR & Average fabric thickness at 9,800 Pa and the average fabric & $\mathrm{mm}$ \\
& Thickness at $196 \mathrm{~Pa}$, after steaming and conditioning \\
B-1 & Bending rigidity in longitudinal direction & $\mu \mathrm{N} . \mathrm{m}$ \\
B-2 & Bending rigidity in transversal direction & $\mu \mathrm{N} . \mathrm{m}$ \\
E100-1 & Extensibility in longitudinal direction at $100 \mathrm{gf} / \mathrm{cm}$ & $\%$ \\
E100-2 & Extensibility in transversal direction at 100gf/cm & $\%$ \\
\hline
\end{tabular}

Table 2 Performance test results (see Table 1 for SiroFAST acronyms)

\begin{tabular}{|c|c|c|c|c|c|c|c|c|c|}
\hline \multicolumn{2}{|l|}{ Property } & $\begin{array}{c}\text { SiroFAST } \\
\text { acronym }\end{array}$ & $\begin{array}{l}\text { Heavy } \\
\text { drill }\end{array}$ & Muslin & $\begin{array}{l}\text { Raised } \\
\text { cotton }\end{array}$ & Jersey & Poplin & Voile & Buckram \\
\hline \multicolumn{2}{|l|}{$\begin{array}{l}\text { Thermal } \\
\text { conductivity } \\
(\mathrm{W} / \mathrm{mK})\end{array}$} & N/A & 0.08 & 0.06 & 0.06 & 0.07 & 0.10 & 0.08 & 0.06 \\
\hline \multicolumn{2}{|l|}{$\begin{array}{l}\text { Effusivity } \\
\left(\mathrm{W} \sqrt{ } / \mathrm{m}^{2} \mathrm{~K}\right)\end{array}$} & N/A & 174.40 & 118.40 & 107.80 & 138.20 & 240.40 & 175.60 & 107.40 \\
\hline \multirow{2}{*}{\multicolumn{2}{|c|}{$\begin{array}{l}\text { Fabric thickness - } \\
\text { FAST-1 (mm) }\end{array}$}} & $\mathrm{T} 2$ & 1.060 & 0.392 & 2.063 & 1.047 & 0.274 & 0.263 & 0.770 \\
\hline & & T100 & 0.779 & 0.237 & 0.918 & 0.637 & 0.149 & 0.183 & 0.731 \\
\hline \multirow{2}{*}{\multicolumn{2}{|c|}{$\begin{array}{l}\text { Surface thickness } \\
\text { FAST-1 (mm) }\end{array}$}} & ST & 0.28 & 0.16 & 1.15 & 0.41 & 0.13 & 0.08 & 0.04 \\
\hline & & STR & 0.37 & 0.19 & 1.33 & 0.48 & 0.17 & 0.10 & 0.22 \\
\hline \multirow{2}{*}{\multicolumn{2}{|c|}{$\begin{array}{l}\text { Bending rigidity } \\
\text { FAST-2 ( } \mu \text { N.m) }\end{array}$}} & $\mathrm{L}^{\mathrm{a}}$ & 183 & 50 & 117 & 9 & 64 & 9 & - \\
\hline & & $\mathrm{T}^{\mathrm{b}}$ & 120 & 6 & 52 & 4 & 38 & 7 & - \\
\hline \multirow{7}{*}{$\begin{array}{l}\text { Extensibility } \\
\text { (\%) FAST-3 }\end{array}$} & \multirow{2}{*}{5} & $\mathrm{~L}$ & $-{ }^{d}$ & - & - & 11 & - & - & - \\
\hline & & $\mathrm{T}$ & - & - & - & 10.9 & - & - & - \\
\hline & \multirow{2}{*}{20} & $\mathrm{~L}$ & - & - & - & 8.2 & - & 0.1 & - \\
\hline & & $\mathrm{T}$ & - & 0.7 & 0.3 & 19.5 & - & 0.7 & - \\
\hline & \multirow{2}{*}{100} & $\mathrm{~L}$ & 0.2 & 0.1 & 0.8 & 18.0 & - & 1.9 & - \\
\hline & & $\mathrm{T}$ & 0.3 & 2.6 & 2.3 & 20.0 & 0.1 & 5.2 & - \\
\hline & 5 & Bias $^{c}$ & - & 10.3 & 0.4 & 3.7 & 0.1 & 1.8 & - \\
\hline \multicolumn{2}{|l|}{$\begin{array}{l}\text { Shear rigidity } \\
\text { (N.m) }\end{array}$} & Bias & - & 12 & 308 & 33 & 1,051 & 68 & - \\
\hline \multirow{2}{*}{\multicolumn{2}{|c|}{$\begin{array}{l}\text { Formability } \\
(\mathrm{mm})\end{array}$}} & $\mathrm{L}$ & - & - & - & 4.5 & - & 0.1 & - \\
\hline & & $\mathrm{T}$ & - & 0.3 & 0.9 & 2.5 & - & 0.3 & - \\
\hline
\end{tabular}

Notes: ${ }^{a} \mathrm{~L}=$ longitudinal.

${ }^{\mathrm{b}} \mathrm{T}=$ transversal.

${ }^{\mathrm{c}}$ Bias $=$ At $45^{\circ}$ from the longitudinal direction of the fabric.

${ }^{\mathrm{d}}$ Measurements not made possible due to the sensitivity of the equipment. 
Figure 3 Visualisation of the results from Table 2

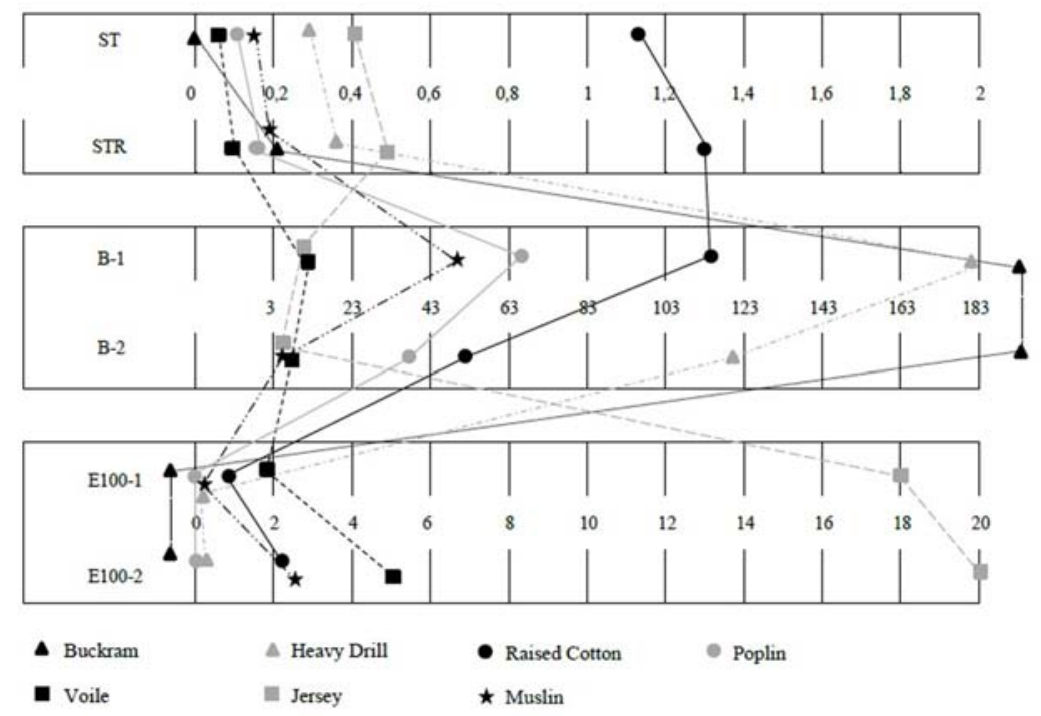

The results presented in Figure 3 and Table 2 are compared to subjective testing in Section 6. Figure 3 enables the visualisation of results obtained and facilitates comparison between fabrics' behaviour, such as the least extensible fabric being Buckram and the most Jersey.

\section{Communication level: subjective human perception of textile materials}

While searching for the vocabulary used by both experts and non-experts, a series of Design Games (Brandt, 2006; Brandt et al., 2008; Bang, 2009) provided purely subjective, qualitative human perceptions of the cotton textile set. Two main methods have been utilised in this level: Design Game 1 is a free elicitation method that allows the vocabulary to emerge from participants; Design Game 2 explores how participants discriminate physical properties of textiles using set scales. In our case study, this allows us to explore whether the vocabulary to see of experts and non-experts overlap. In addition it was used to explore if the language used reflected the physical properties of the textile materials as measured through objective testing (Section 3).

\subsection{Game method}

\subsubsection{Design game with non-experts}

Here two experiments were run simultaneously: Design Game 1 - exploring the vocabulary used by consumers at the communication level of the framework, and Design Game 2 - exploring how designers and consumers discriminate at the physical level of the framework. 
Thirty-nine participants took part in the study (17 male, 22 female, aged between 18 and 40), again limited to fluent English speakers. Two or three participants at a time were seated in a neutral, relaxed environment. Each was presented with a set of A4 size, numbered cotton samples, laid on a table. There were two parts to the design games:

"Design Game 1. A two-minute brainstorming session to familiarise participants with the textile set and to generate their own bipolar descriptive scales took place. Participants were then asked to feel the textile set and identify as many opposite pairings as they could, and describe their relationship using their bipolar descriptors. The researchers registered the numbered of different pairings generated."

Next participants were asked collectively to decide where to place the number referring to each of the seven swatches (Figure 4) on predetermined polar scales (Figure 5).

"Design Game 2. This activity was conducted as a group activity with non-experts. As this is not a common activity for them the proposition was to facilitate engagement in the task.

Figure 4 Set of seven cotton textiles numbered for design games (see online version for colours)

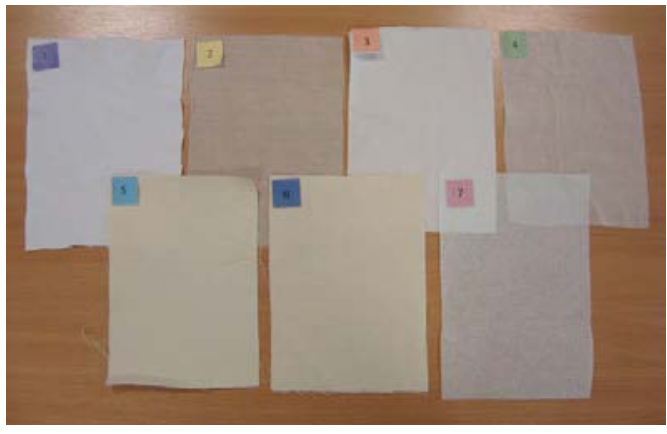

Figure 5 Bipolar scales on board used for design games (see online version for colours)

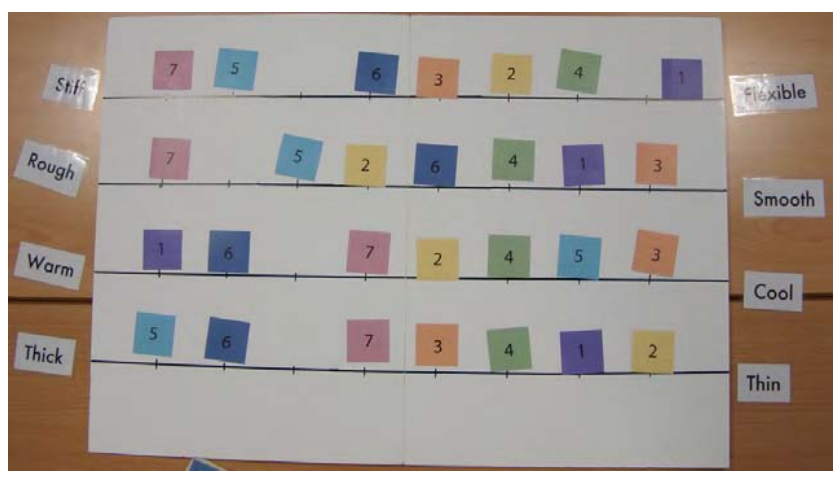




\subsubsection{Design game with experts}

Seven females participated in the study (aged between 20 and 50) and limited to fluent English speakers, who clearly understood the meanings of the eight-bipolar descriptors. Participants were individually seated in a neutral, relaxed environment. Each was presented with a set of A4 size, numbered cotton samples, laid on a table.

Participants were asked to place the number referring to each of the seven swatches (Figure 4) on predetermined polar scales (Figure 5).

\subsection{Design game results}

\subsubsection{Design game with non-experts results}

Non-expert participants generated 41 different bi-polar pairings describing the cotton textile set. The incidence of their usage can be seen in Table 3 (cases only used once are not shown):

Table 3 Bi-polar pairs used in design games with non-experts part 1

\begin{tabular}{lc}
\hline Bipolar pair & Incidence of usage \\
\hline Thick-Thin & 7 \\
Rough-Smooth & 6 \\
Soft-Hard & 4 \\
Warm-Cool, heavy-light and soft-coarse & 3 \\
Warm-Cold and cheap-expensive & 2 \\
\hline
\end{tabular}

The bipolar pairs thick-thin, followed by rough-smooth were the most widely used by non-experts. This concurs with the findings of the initial literature review, which demonstrated that among experts and researchers rough-smooth and soft-hard were jointly the most commonly used term pairings, followed by thick-thin. Soft-Hard is the third most commonly used term pairing in our design games. Whilst the research team expected that this pairing was too easily confused with rough-smooth and stiff-flexible, these results demonstrate that it is a valid pairing in its own right.

Although thermal properties were included, their descriptions differed slightly. They still formed part of the top five most commonly used bipolar pairings for un-trained consumers. The only bipolar term pairing, which was in common usage in the literature review but not by un-trained consumers was stiff-flexible.

The results of the scale placement section of the non-experts game have been presented in graphs to show the distribution of the textiles, which can be seen in Figure 6; the results are discussed below. 
Figure 6 Distribution of textiles per scales in design game with non-experts (see online version for colours)
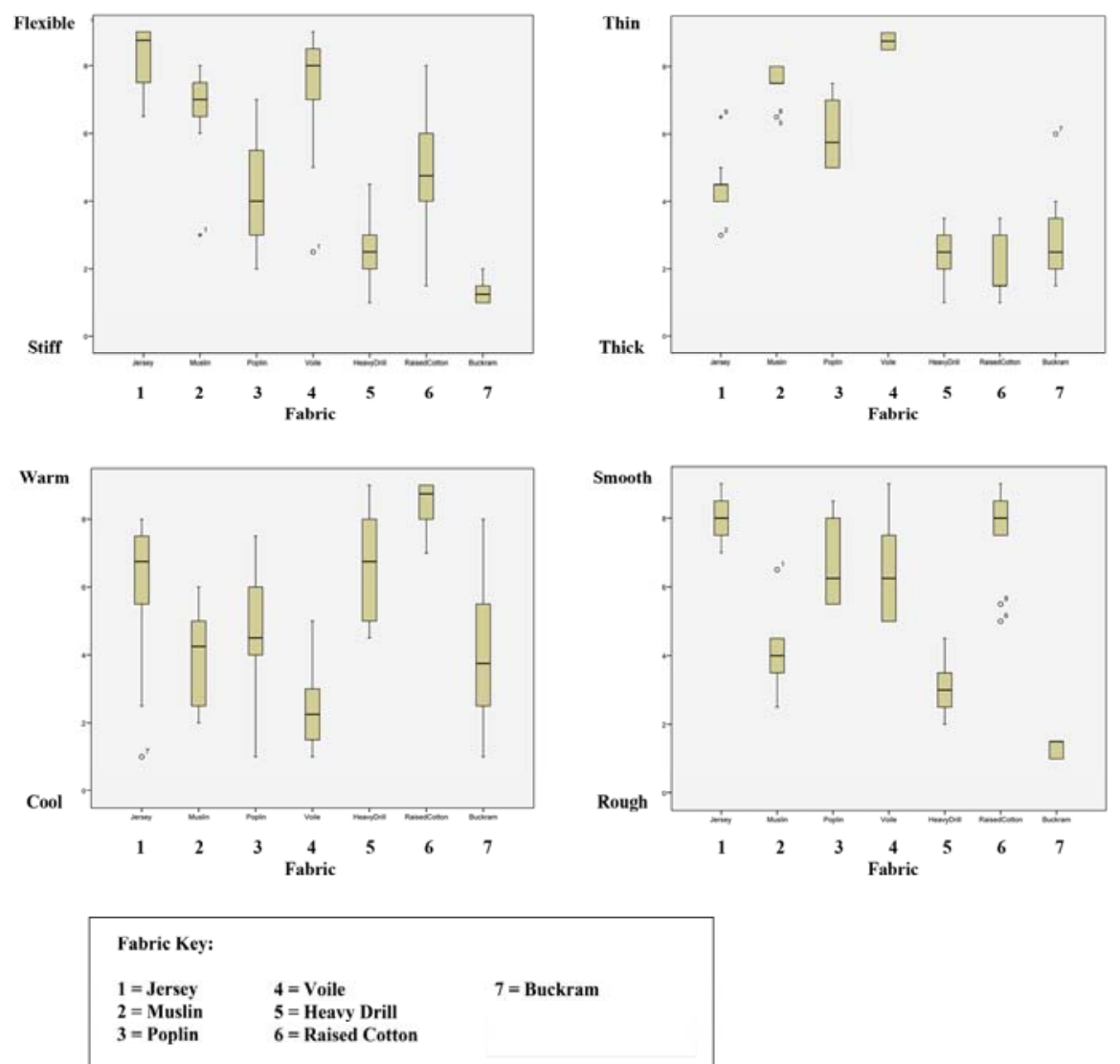

\subsubsection{Warm-Cool}

Ratings on the warm-cool scale again showed the most variability, as reflected in the length of the error bars in Figure 6. The most consistently rated textile was raised cotton, which was also perceived to be the warmest. Following raised cotton in order of warmest to coolest were heavy drill, jersey, poplin, muslin, Buckram and voile.

Ratings for buckram on this scale were extremely varied, indicating a greater than average difficulty in rating this textile on the warm-cool scale.

\subsubsection{Thick-Thin}

Ratings on this scale were the least variable, showing that consumers were most consistent in their perceptions of thickness. Ranking of textiles was from thickest to thinnest raised cotton, heavy drill, Buckram, jersey, poplin, muslin and voile. 


\subsubsection{Stiff-Flexible}

This scale also showed a high degree of variability with poplin and raised cotton the most varied in their rating (see Figure 6). Ranking of textiles was from stiffest to flexible Buckram, heavy drill, poplin, raised cotton, muslin, voile and jersey.

\subsubsection{Rough-Smooth}

Ranking of textiles was from roughest to smoothest Buckram, heavy drill, muslin, voile, poplin, jersey and raised cotton (see Figure 6).

\subsubsection{Design game with experts results}

The results of the scale placement section of the game with experts have been presented in graphs to show the distribution of the textiles, which can be seen in Figure 7; the results are discussed below.

\subsubsection{Warm-Cool}

Ratings on the warm-cool scale showed the most variability, as reflected in the length of the error bars in Figure 7. The most consistently rated textile was raised cotton, which was also perceived to be the warmest. Following raised cotton in order of warmest to coolest were jersey, heavy drill, muslin, poplin, voile and Buckram. Ratings for Buckram on this scale were considerably varied.

\subsubsection{Thick-Thin}

Ratings on this scale were most variable for Buckram but showed a lower variability for other fabrics (Figure 7). Ranking of textiles was from thickest to thinnest raised cotton, heavy drill, Buckram, jersey, poplin, muslin and voile.

\subsubsection{Stiff-Flexible}

This scale also showed a high degree of variability with Voile being the most varied in rating (see Figure 7). Ranking of textiles was from stiffest to most flexible Buckram, heavy drill, poplin, raised cotton, muslin, voile and Jersey.

\subsubsection{Rough-Smooth}

In this scale experts were most consistent in their perceptions. Ranking of textiles was from roughest to smoothest Buckram, heavy drill, muslin, poplin, voile, raised cotton and jersey (see Figure 7). 
Figure 7 Distribution of textiles per scales in design game with experts (see online version for colours)
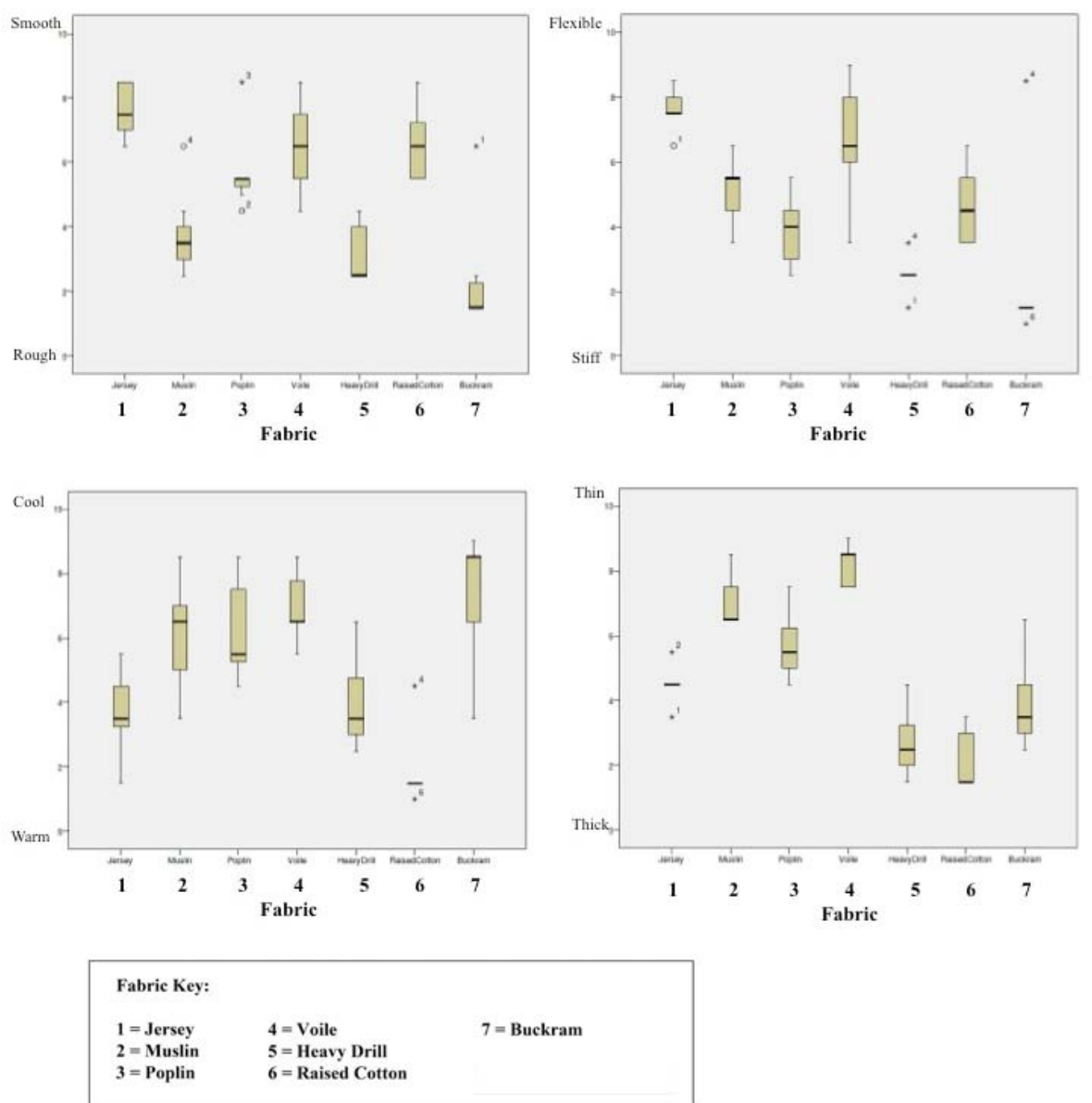

\section{Perceptual space level: capturing semantic and emotional differences}

The game study was complemented by a follow up study using a more structured approach. The aim was to holistically identify the dimensions and their relationship, characterising how people evaluate tactile experience of textiles. The experiment used a triadic comparison approach (Bang, 2009) that allows participants to describe their subjective perception by comparing textiles within a triad. A comparative approach was used as it made it easier for un-trained participants to describe their subjective experience. In our framework this reveals the most relevant dimensions of the tactile experience compared to user generated tactile descriptors (communication level) and the objectively measured textile properties (physical level). 


\subsection{Triadic comparison method}

Textiles for the triad were each cut to a standard length and folded into a double and a single layer (Figure 8) and hung on a rail simulating the experience of participants interacting with garments in a shop environment. The rationale for this being that when buying garments it is very rare for a consumer to handle only a single layer of textile.

These were then presented in a random order to each participant in all possible triads of the seven cotton textiles, supplying each participant with 35 trials. At each trial, the participants were asked to evaluate a triad of textiles by focussing on the differences between them. They were also asked to answer two questions: first, to pick the two most similar textiles. Second, they were asked to identify among the eight bipolar descriptors the one that better described the way in which the two similar textiles differed from the odd one.

Figure 8 Schematics for the presentation of textiles

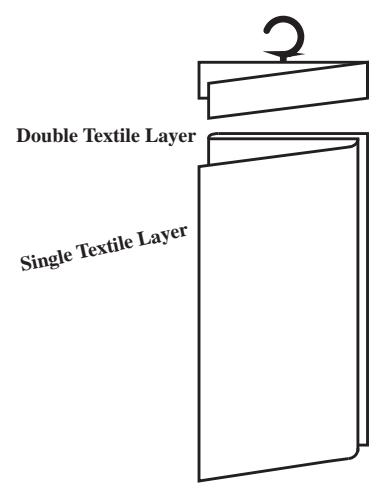

A total of 39 participants, 20 male and 19 female, between the ages of 18 and 40 took part in the study. This sample was limited to fluent English speakers to make sure that the meanings of the 8 bipolar descriptors were clearly understood. After completing the rating of all 35 triads, participants were asked to rate the textile samples on a scale from 'favourite' to 'least favourite'. The reason for this question was to investigate the role of textile preferences in the evaluation of their tactile properties.

\subsection{Triadic comparison results}

The number of times each textile sample was chosen as the odd sample was taken as an estimate of the distance of the sample from the other two samples it was compared with. This provided a set of estimated dissimilarity matrices, one for each participant. The histogram in Figure 9 shows the number of times a textile was associated to one label minus the number of times it was associated to the opposite label by the various participants pooled together. The dissimilarity matrices were used as input to the Multidimensional Scale routine in the SPSS20 statistical analysis software: the INdividual Difference SCAling (INDSCAL) method with chi-squared measure. The INDSCAL results provided the coordinates for the stimuli in a perceptual space defined by the set of dimensions that account for most of the variance contained in the data. 
Figure 9 Subjective perception of fabric characteristics

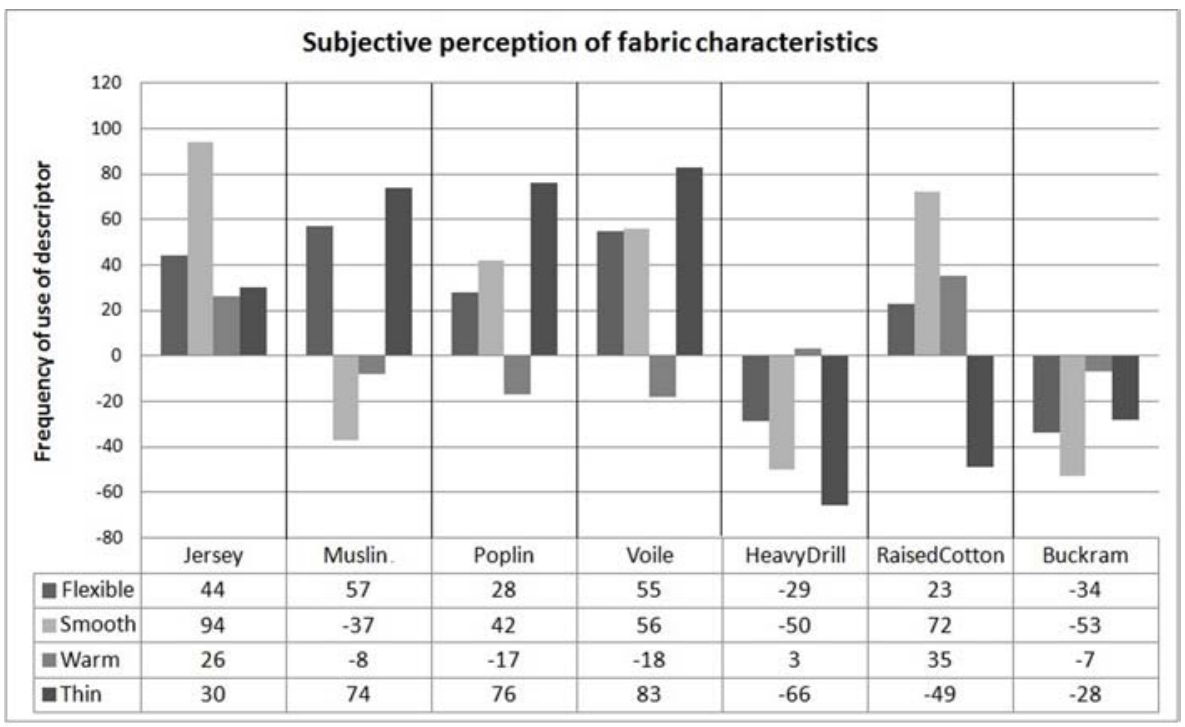

The fitness measure for different INDSCAL methods shows that an acceptable Kruskal's Stress measure [ $<.15$ according to Kruskal and Wish (1978) rule of thumb] is reached already with three dimensions. Each dimension explains respectively: 29\%, 27\% and $19 \%$ of the variance for a total of $75 \%$ of variance.

Figure 10 presents the results of the INDSCAL method showing the position of the seven textiles in the identified three-dimensional models. The distance between pairs of textiles (points in the space) represents how different the textiles were perceived to be. The higher the distance along one dimension the higher the difference according to that dimension.

In order to explore if the bipolar descriptors form a judgement structure to the configuration stimuli, we used the labelling assigned by the participants during the triad experiments (summarised in Figure 11) to clarify the dissimilarity of the odd (most dissimilar) textile to the other two textiles. Dimension 1 of the perceptual space in Figure 10(b) appears to reflect the degree of perceived smoothness of the textile. In fact, if we look at the projected positions of the samples along dimension 1, we can identify three clusters of textiles: the smoother ones on the right side, the least smooth ones on the left side, and at the centre the three remaining textiles. Similarly, the flexible-stiff dimension appears as the diagonal of the 2D stimulus configuration formed by dimension 1 and dimension 2 [Figure 10(c)]. We can see the stimulus projected along such dimensions reflect the flexible-stiff similarity judgements in Figure 10. The third dimension that emerged from the model is the thin-thick dimension. This is the diagonal of the space formed by dimensions 2 and 3 [Figure 10(c)]. 
Figure 10 3D model: derived stimulus configuration

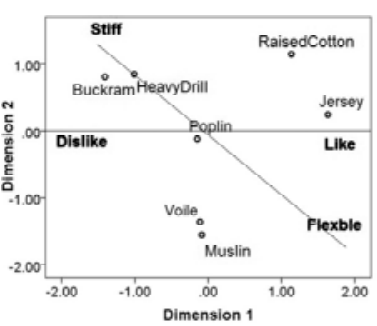

(a)

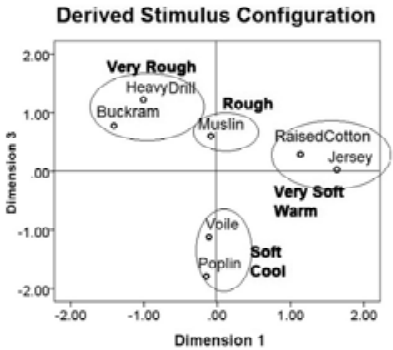

(b)

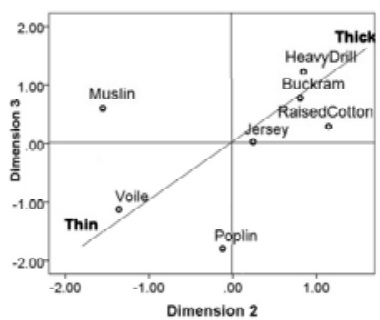

(c)

These results indicate that non-experts made use of at least three of the four proposed bipolar descriptor sets when comparing textile hand. The warm-cool dimension did not appear in the model. This could suggest that for un-trained participants the warm-cool dimension is not one of the main criteria by which they evaluate textiles (Smith, 1986). In fact, Figure 11 shows that the descriptors warm and cool were either less used by the participants or used inconsistently. This was also the case for the four and five dimension models. We analysed the frequency of use of each pair of descriptors. Figure 11 shows that the bipolar descriptors warm-cool were much less used (11\% of the time) than the other bipolar descriptors ( $>23 \%$ of the time). This appeared to be also the case for the game study. In the second part of the game study the term pair warm-cool was less consistently used than the other others pairs of descriptors (see longer boxplots). This could be due to the fact that warm-cool is easier to assess in wearer trials, being relevant for thermophysiological assessments; in that respect, Smith (1986) claims that "Handle observations can detect differences between most fabrics in respect of fabric structure, drape, finish, and so on, but they are unable to assess fabric surface hairiness, thermal insulation moisture-transfer properties, and garment fit”.

Figure 11 Frequency of use of descriptors

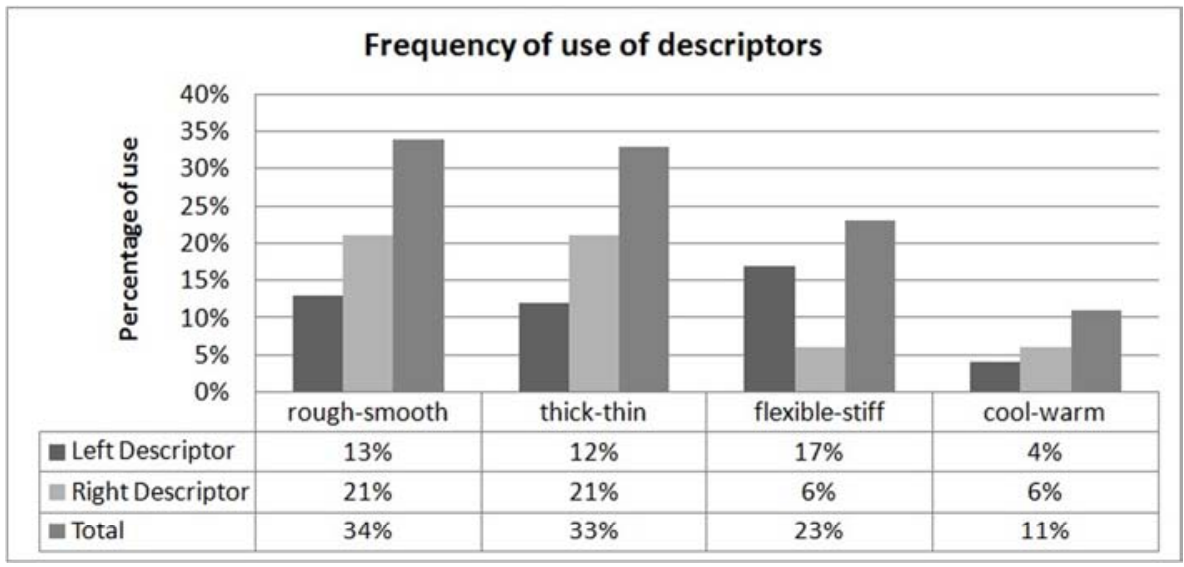


Finally, we explored if the preference ratings fitted within the INDSCAL space. The Boxplot in Figure 12 represents the preference rating for the seven textiles. We can see that the ranking of preference shown by these boxplots corresponds to the ranking of the samples along dimension 1 (Figure 10).

Figure 12 Preference ratings (see online version for colours)
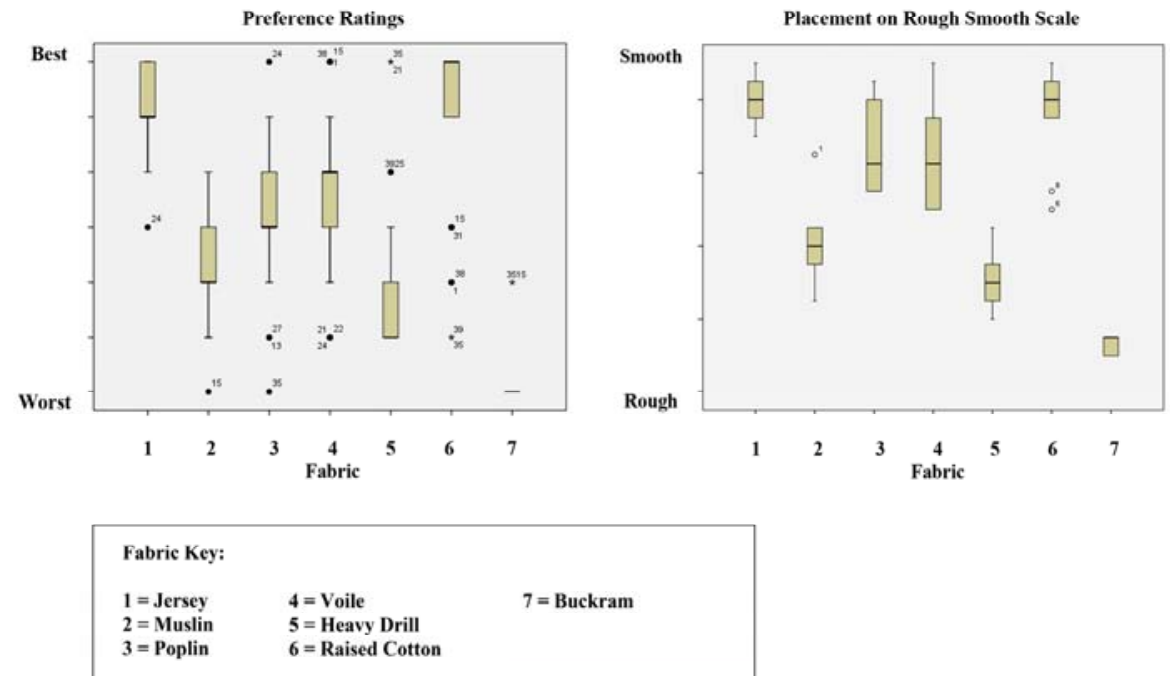

\section{Correlation of results}

The results of all studies are collated in Figure 13. Figure 13 shows how the subjective and objective perceptions of participants relate to the objectively measured physical properties.

There is a strong relation between textile experts and un-trained consumers in their grouping of fabrics. Further Spearman's rank correlations with objective, mechanised testing are shown in Table 4.

The non-parametric Spearman's rho test was used to measure the correlation between the rankings obtained through each group of measurements. For the non-objective measures, the median values of the rating of the participants were used. In order to compute the correlations, the subjective ratings were first inverted to reflect the direction of the corresponding objective scales. One-tail correlation values were hence computed as positive correlation where hypothesised. Table 4 shows the correlation values. 
Figure 13 Collated results of testing tactile properties (see online version for colours)

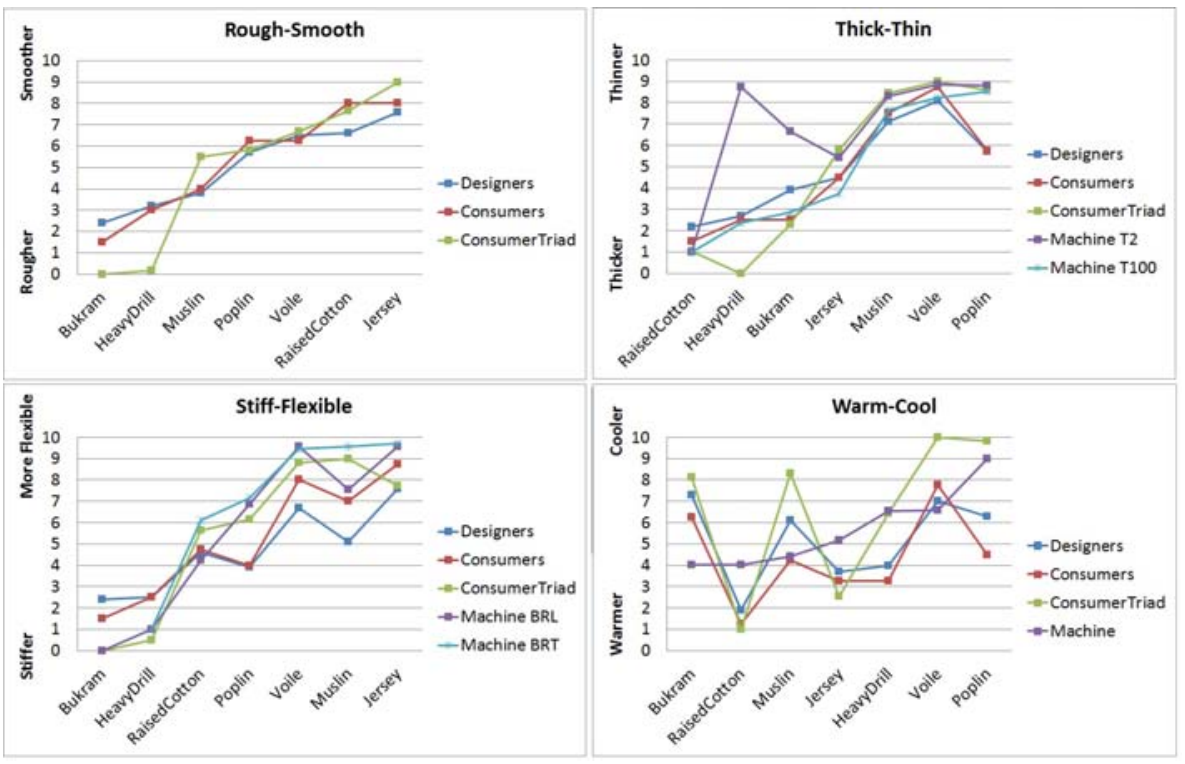

Notes: T2: fabric thickness $\left(2 \mathrm{gf} / \mathrm{cm}^{2}\right)$; T100: fabric thickness $\left(100 \mathrm{gf} / \mathrm{cm}^{2}\right)$; $\mathrm{BRL}=$ bending rigidity longitudinal; BRT = bending rigidity transversal)

Table 4 Spearman's rho correlation values between subjective ratings and objective testing data

\begin{tabular}{|c|c|c|c|}
\hline \multicolumn{4}{|c|}{ Spearman's rank correlation (one-tail p-value) } \\
\hline $\begin{array}{l}\text { Descriptors } \\
\text { scales }\end{array}$ & $\begin{array}{l}\text { Consumers (design game) vs. } \\
\text { objective measurements }\end{array}$ & $\begin{array}{l}\text { Consumers vs. } \\
\text { trained experts }\end{array}$ & $\begin{array}{l}\text { Trained experts vs. } \\
\text { objective measurements }\end{array}$ \\
\hline \multirow{3}{*}{ Flexible-Stiff } & $\begin{array}{l}\text { - Bending rigidity L: } \\
\mathrm{r}=-.928^{* *}\end{array}$ & \multirow[t]{3}{*}{$\begin{array}{l}\text { Stiff-flexible: } \\
\quad r=1.0^{* *}\end{array}$} & $\begin{array}{l}\text { - Bending rigidity L: } \\
\mathrm{r}=-.928^{* *}\end{array}$ \\
\hline & $\begin{array}{l}\text { - Bending rigidity } \mathrm{T} \text { : } \\
\mathrm{r}=-.886^{*}\end{array}$ & & $\begin{array}{l}\text { - Bending rigidity } \mathrm{T} \text { : } \\
\mathrm{r}=-.886^{* *}\end{array}$ \\
\hline & $\begin{array}{l}\text { - Extensibility 100T: } \\
\mathrm{r}=.943^{* *}\end{array}$ & & $\begin{array}{l}\text { - Extensibility 100T: } \\
\mathrm{r}=-.943^{* *}\end{array}$ \\
\hline \multirow{4}{*}{ Thick-Thin } & - Thickness T2: $\mathrm{r}=-.901^{* *}$ & \multirow{4}{*}{$\begin{array}{l}\text { Thick-Thin: } \\
\mathrm{r}=.991^{* *}\end{array}$} & - Thickness T2: \\
\hline & - Thickness T100: $\mathrm{r}=-.883^{* *}$ & & 929 \\
\hline & - & & $\begin{array}{l}\text { - Thickness T100: } \\
\mathrm{r}=-.883^{* *}\end{array}$ \\
\hline & & & $\begin{array}{l}\text { - Surface thick. STR: } \\
\mathrm{r}=-.857^{* *}\end{array}$ \\
\hline
\end{tabular}

Note: Only statistically significant correlations are reported. 
Table 4 Spearman's rho correlation values between subjective ratings and objective testing data (continued)

\begin{tabular}{|c|c|c|c|}
\hline \multicolumn{4}{|c|}{ Spearman's rank correlation (one-tail p-value) } \\
\hline $\begin{array}{l}\text { Descriptors } \\
\text { scales }\end{array}$ & $\begin{array}{l}\text { Consumers (design game) vs. } \\
\text { objective measurements }\end{array}$ & $\begin{array}{l}\text { Consumers vs. } \\
\text { trained experts }\end{array}$ & $\begin{array}{c}\text { Trained experts vs. } \\
\text { objective measurements }\end{array}$ \\
\hline Warm-Cool & $\begin{array}{l}\text { - No correlation for thermal } \\
\text { measures } \\
\text { - Thickness ST T2: } \mathrm{r}=.847^{* *} \\
\text { - Surface thickness ST: } \mathrm{r}= \\
.919^{* *} \\
\text { - Surface thick. STR: } \\
\mathrm{r}=.847^{* *}\end{array}$ & $\begin{array}{l}\text { Warm-Cool: } \\
\mathrm{r}=.919^{* *}\end{array}$ & $\begin{array}{l}\text { - No correlation for } \\
\text { thermal measures } \\
\text { - Thickness T2: } \\
\mathrm{r}=.750^{*} \\
\text { - Surface thickness ST: } \\
\mathrm{r}=-1.0^{* *} \\
\text { - Surface thickness STR: } \\
\mathrm{r}=-.786^{* *}\end{array}$ \\
\hline Rough-Smooth & Not available & $\begin{array}{l}\text { Rough-Smooth: } \\
\quad \mathrm{r}=.982^{* *}\end{array}$ & Not available \\
\hline
\end{tabular}

Note: Only statistically significant correlations are reported.

All the correlation values between experts and non-experts are very high $(r>.9)$ and all statistically significant $(\mathrm{p}<.01)$. The correlations between objective measurements and either experts or non-experts subjective perceptions are very high for all scales $(|r|>.7)$ except the warm-cool scale. The warm-cool scale, which according to the literature should be related to thermal conductivity and effusivity, is the only one not to show any correlation with the subjective perceptions; interestingly, however, the subjective perception for both experts and non-experts closely correlated with thickness measurements (T2, T100, ST and STR), demonstrating that human evaluators (independently of their training) may link thickness of a textile to thermal transmission and thus retention of heat. On the perceptual scale of warm-cool in the design gaming process, raised cotton has been rated warmest and voile coolest. Objective measurement for effusivity ranks raised cotton and voile second warmest and second coolest respectively. The fact that these were the most accurately subjectively rated textiles on this scale in relation to objective testing seems to confirm the MDS indication that this is the least understood perceptual scale.

Thick-Thin scale has more significantly correlated to thickness (T2 and T100) than to surface thickness (ST) measurements. There is low similarity between the objective testing results for ST (Figure 1, ST and STR) and the Thick-Thin scale in the INDSCAL model. This lack of similarity to the objective results can also be seen in the rating scales generated in Design Games (see Figure 6).

The thick-thin and warm-cool scales show the most variation in ratings of Buckram and muslin. Interestingly, these are both fabrics with a particularly open weave structure, indicating that visual judgements of density may have influenced their rating.

The stiff-flexible scale shows high correlation between objective and subjective analysis, with all results other than longitudinal and transversal extensibility (L100 and T100) in correlation to Triadic comparison proving significant (see Table 4). Stiffness and flexibility was not a commonly used scale in our design game process, however in the INDSCAL plot (Figure 10) it is one of the scales characterising the stimulus configuration, meaning that even if not spontaneously used, it is a well understood scale. When comparing the objective testing results of bending rigidity (Figure 2, B1 and B2) to 
the rating of the textiles on the stiff-flexible INDSCAL scale it appears that participants were highly accurate at placing textiles on this perceptual scale and a significant relationship can be observed. This may be confirmed by the fact that the term stiff was used three times in the term pairing 'brainstorm' design game (giving it a higher than average incidence of usage for a single term) but was only paired with the term flexible once. On other occasions it was paired with 'Loose' and 'Stretchy'.

Buckram has been rated with most variability in all scales. This may be due to the fact that Buckram is the least familiar of the textiles. Studies have shown that user perceptions of man made materials are dependent on how familiar they seem and how natural they are perceived to be (Georgiev and Nagai, 2001).

Overall participants were good at discerning the extremes of all perceptual scales, but do not seem to be accurate in the judgement of perceptions in between these extremes. However, we are not aware of how accurate their perception is, and how much variance they are able to distinguish in properties. E.g., a difference in thickness of $0.01 \mathrm{~mm}$ may not be relevant to touch assessment. Nevertheless, Smith (1986) asserts that hand evaluations are more accurate than wear trials.

The two most used rating scales in the brainstorm design game were thick-thin and Rough-Smooth. This is also confirmed by the triadic experiment and Figure 11 shows that these two bipolar scales were the most used. There is no objective data for correlation to rough-smooth ratings; still Spearman's correlation results for the thick-thin scale show a high degree of overall correlation, excluding ST, between untrained consumer and objective testing. This would imply that it is well understood, perhaps explaining it's frequent usage. Stiff-Flexible has similar, if not greater correlation however.

\subsection{Preference}

In addition to the similarity data a strong link can be observed between the Rough-Smooth scale and preference ratings (Figure 12). It is therefore very likely that this perceptual dimension is the most influential in forming preferential judgements of textiles, though their end use should be considered as an influencing factor. Participants were not informed of any usage context for the textiles during these studies. Soufflet et al. (2004) link preference to the perceptual term pairing they translate as Soft-Harsh, more correctly translated as Soft-Rough. Seemingly, the same haptic perception as Rough-Smooth and therefore lending support to our findings if translated correctly. Conversely pre-study comments recorded by Fenko et al. (2010) suggested that comfort affected the perceived warmth of a textile. This would imply that the warm-cool scale should be linked to preference and roughness-smoothness, a hypothesis, which our results do not support.

\subsection{Discussion}

In this paper, we have proposed a framework to probe the relationship between tactile perceptions and physical properties of textile materials. Through the case study we demonstrated that our participants detected the physical properties of the textiles, leading to a generally high degree of correlation between their perceptions and subjective and objective ratings as tested at the physical level of the framework. We suggest, therefore, 
that the correlations identified between different human and mechanical evaluations of perceived textile hand qualities corroborate the use of accessible studies of perception, such as those used in our non-expert studies. In this case Design Games and triadic comparison are used at the perceptual space and communication levels of the framework. These methods give sufficiently accurate results that we propose they can be used independently by designers who need cheap and accessible methods to explore perceptions of materials. Equally if they require a deeper, more holistic insight the methods can be combined to discover how the material qualities are physically perceived, how the perceptual space they inhabit is understood and communicated. This is particularly useful for designers hoping to ensure they communicate a brand or design message through their material choices, but who do not have access to mechanised testing.

We have shown the importance of including human assessments, as they indicate the level of accuracy which may be sufficient in objective testing to provide useful data to a human evaluator (i.e., differences of a certain level may not be perceptible or relevant) as well as revealing meaningful parameters (i.e., to highlight relevant dimensions of the experience). From our experimental results, the stiff-flexible bipolar pair has best illustrated this, considering that participants were highly accurate at placing textiles on this scale at both perceptual space and communication levels of the framework and a significant correlation with objective (physical) testing can be observed. This scale may be easily understood and discerned by touch. However, when assessing fabrics against the warm-cool scale confusion was observed amongst participants. Correlation results indicate that both un-trained consumer and trained expert perceptions of warm-cool do not correlate to the objective testing results for thermal effusivity and conductivity, rather they correlate to thickness measurements. This may indicate that for certain characteristics participants' perceptions, irrespective of their level of training, could be the result of a combination of objectively measurable properties and tacit associations, which suggests a vast field for future research. Arguably this verification of human subjective intuition may imply that some objective mechanised testing procedures must change to become better predictors of human perception and not vice versa.

In relation to the methods usage, the design games may help designers to design better products, as they strive to be ever closer to the people they are designing for. They can inform designers wishing to conduct user studies, and can help guide their choice of investigative process without the need for mechanised testing. This is particularly true for the textile and apparel industries, however the multi-dimensional approach discussed will also be valuable if applied to testing of other materials with users, in consumer focussed product design and co-design processes involving a multidisciplinary team. Any design process that requires communication between materials scientists, designers and product technologists will benefit from the use of this approach. This is particularly vital in industries such as Fashion where design education rarely encompasses technical aspects such as fibre development and materials characterisation. Systems such as the SiroFAST were developed as a means to communicate between product developers and provide quality assurance in textile manufacture, however these are rarely used by designers as they are technical and unintuitive, and require specialist equipment and knowledge for the evaluation of results.

We propose that the design community can use the non-expert study methods (Triadic Comparison or Design Gaming) to conduct their own investigations into how consumers perceive tactile properties knowing that the results are reliable. This has the potential to 
change the way we communicate. We hope that the easy, low cost methods of studying tactile perception (which we have shown to be reliable) will allow more intuitive communication between materials scientists interested in the mechanical properties and characteristics of materials, and designers who are interested in the sensory and aesthetic impact of these materials on the people they are designing for.

We hope that we have gone some way towards addressing the problems of communicating textile hand properties as emphasised by Cardello et al. (2003), who highlight the lack of theoretical models in this research field.

\section{Limitations}

We sought to test the perceptions of un-trained consumers naturalistically as they would experience textiles in a retail environment, however this did not allow us to explore the accuracy of their sense of touch independently of other modalities, particularly vision. Further research may help us to answer how small a difference in the objective properties of a textile an untrained evaluator can perceive. It may also be appropriate to test whether un-trained consumers rate textiles more closely to objective testing results when using prescribed handling and manipulation methods such as those suggested by the AATCC Evaluation Procedure 5 (2006).

Kim and Winakor (1996) also suggest that unipolar perceptual scales are more intuitive for participants than bi-polar scales. Although this is not standard descriptive practice in the textile industry, further study with unipolar perceptual scales may clarify the usage of terms such as Warm and Cool. This scale was not well understood, however as separate descriptors consumers may better understand and utilise the terms warm and cool.

In future studies, it would also be pertinent to include descriptive terms with an emotional component. The concurrence between preference ratings and the rough-smooth perceptual scale demonstrates that such perceptions cannot be excluded from appreciation of textile hand. While in this study we sought to limit the investigation to terms relating to physical properties, this may in-fact prove to artificially restrict terms that participants naturally use as they may not see any distinction in the descriptive utility of hedonic and non-hedonic terms.

\section{Conclusions}

In this work, we have proposed the tactile triangle framework to access people's tactile experience with textiles. Through the case study we investigated the relation between subjective and objective assessments of tactile properties of textiles by different parties (trained designer, un-trained consumer and machine). By allowing comparisons to be drawn between all three, we thus fill the current gaps in research in this area.

The main strength of the proposed tactile triangle framework is that, as the case study demonstrates, perceptual data gained from methods used to investigate each of the levels largely corresponds to the data gained through other levels and methods. Thus the tactile triangle can be applied integrally or in parts according to the research question being pursued (e.g., if the interest lays in investigating what language a population uses, then 
design games can be used, especially if time is a constraint; if the focus is on important dimensions for the experience, then triads are better suited; or if the interest is in the correlation to objective measures, then design games and physical testing can be employed).

\section{Future work}

As the textiles used for the case study were dissimilar in nature, in future we want to investigate if, for fine grain levels of comparison, this framework will still be useful, e.g., comparing two fabrics that are very similar to test if the consumer and designer differ in their perceptions.

Our case study attempts to relate the perceptions of experts to consumers, enabling them to communicate via a shared understanding of the tactile properties of textiles. Such communication is increasingly digital, therefore we intend our methodology to inform digital communication around the tactile properties of textiles (Hughes et al., 2012) and inform the presentation of digital textile swatches, particularly for touch screen devices (Atkinson et al., 2013; Orzechowski et al., 2011; Petreca et al., 2013). We believe that perception of textile hand is a truly multi-modal experience (Cho et al., 2002; Citrin et al., 2003) and will next investigate the use of other modalities such as images, sounds and even physiological changes.

\section{Acknowledgements}

We would like to thank the RCUK Digital Economy Programme for funding the 'Digital Sensoria: design through digital perceptual experience’ project: grant no. EP/H007083/1 and IPT - 41 Institute for Technological Research of the State of São Paulo together with FIPT - IPT Foundation, São Paulo for sponsoring Bruna Petreca’s involvement in the study.

\section{References}

American Association of Textile Chemists and Colorists (AATCC) Evaluation Procedure 5 (2006) Fabric Hand: Guidelines for the Subjective Evaluation, Developed in 1990, by AATCC Committee RA89.

Atkinson, D., Orzechowski, P., Petreca, B., Bianchi-Berthouze, N., Watkins, P., Baurley, S., Padilla, S. and Chantler, M. (20130 'Tactile perceptions of digital textiles: design research approach', SIGCHI Conference on Human Factors in Computing Systems, Proceedings of 2013 ACM SIGCHI Conference on Human Factors in Computing Systems, doi:10.1145/ 2470654.2466221.

Bang, A.L. (2009) 'Triad as a means for dialogue about emotional values in textile design', 8th European Academy of Design Conference, The Robert Gordon University, Aberdeen, Scotland [online] https://core.ac.uk/download/pdf/14339616.pdf (accessed 29 November 2015).

Bang, A.L. and Nissen, K. (2009) 'Facilitating teamwork in the design process: repertory grid as an approach to exploratory inquiry', Engaging Artifacts, The Oslo School of Architecture and Design, Oslo, Norway [online] http://www.nordes.org/opj/index.php/n13/article/view/50/41 (accessed 29 November 2015). 
Behery, H.M. (2005) Effect of Mechanical and Physical Properties on Fabric Hand, Woodhead Publishing, Cambridge.

Brandt, E. (2006) 'Designing exploratory design games: a framework for participation in participatory design?', in Jacucci, G. and Kensing, F. (Eds.): PDC 2006: Proceedings of the Ninth Conference on Participatory Design, Trento, Italy, pp.57-66, doi: 10.1145/ 1147261.1147271.

Brandt, E., Messeter, J. and Binder, T. (2008) 'Formatting design dialogues - games and participation’, CoDesign, Vol. 4, No. 1, pp.51-64, doi: 10.1080/15710880801905724.

Cardello, A.V., Winterhalter, C. and Schutz, H.G. (2003) 'Predicting the handle and comfort of military clothing fabrics from sensory and instrumental data: development and application of new psychophysical methods', Textile Research Journal, Vol. 73, No. 3, pp.221-237, doi: 10.1177/004051750307300306.

Chen, X., Barnes, C.J., Childs, T.H.C., Henson, B. and Shao, F. (2009) 'Materials' tactile testing and characterisation for consumer products' affective packaging design', Materials and Design, Vol. 30, No. 10, pp.4299-4310.

Cho, G., Kim, C. and Casali, J.G. (2002) 'Sensory evaluation of fabric touch by free modulus magnitude evaluation’, Fibres and Polymers, Vol. 3, No. 4, pp.169-173.

Citrin, A., Stem, D., Spangenberg, E. and Clark, M. (2003) 'Consumer need for tactile input: an internet retailing challenge', Journal of Business Research, Vol. 56, No. 11, pp.915-922.

Das, A., Kothari, V.K. and Nagaraju, V. (2007) 'Frictional characteristics of woven suiting and shirting fabrics', Indian Journal of Fibre and Textile Research, Vol. 32, No. 3, pp.337-343.

De Boos, A. (2005) 'Concepts and understanding of fabric hand', in Behery, H.M. (Ed.): Effect of Mechanical and Physical Properties on Fabric Hand, pp.11-44, Woodhead Publishing, Cambridge.

El-Mogahzy, Y., Kilinc, F.S. and Hassan, M. (2005) 'Development in measurement and evaluation of fabric hand', in Behery, H.M. (Ed.): Effect of Mechanical and Physical Properties on Fabric Hand, pp.45-65, Woodhead Publishing, Cambridge.

Fan, J., Yu, W. and Hunter, L. (2004) Clothing Appearance and Fit: Science and Technology, Woodhead Publishing, Cambridge.

Fenko, A., Schifferstein, H.N.J. and Hekkert, P. (2010) 'Looking hot or feeling hot: what determines the product experience of warmth?', Materials \& Design, Vol. 31, No. 3, pp.1325-1331, doi: 10.1016/j.matdes.2009.09.008.

Georgiev, G. and Nagai, Y. (2001) 'A conceptual network analysis of user impressions and meanings of product materials in design', Materials \& Design, Vol. 32, Nos. 8-9, pp.4230-4240, doi: 10.1016/j.matdes.2011.04.024.

Howorth, W.S. and Oliver, P.H. (1958) 'The application of multiple factor analysis to the assessment of fabric handle’, Journal of the Textile Institute, Vol. 49, No. 11, pp.T540-T553.

Hu, J., Li, Y. and Yeung, K.W. (2006) 'Thermal properties', in Li, Y. and Wong, A.S.W. (Eds.): Clothing Biosensory Engineering, pp.189-205, Woodhead Publishing, Cambridge.

Hughes, L., Atkinson, D., Bianchi-Berthouze, N. and Baurley, S. (2012) 'Crowd-sourcing an emotional wardrobe', CHI2012, Proceedings of the 2012 ACM annual conference on Human Factors in Computing Systems Extended Abstracts, 5-10 May 2012, Austin, Texas USA, ACM Press 2012, New York, doi: 10.1145/2212776.2212801.

Hung, S-H. and Chuang, M-C.A. (1999) Study on the Relationship between Texture Image and Textile Fabrics of Bags, thesis, Institute of Applied Arts National Chiao-Tung University, Hsinchu, Taiwan.

Karana, E. (2009) Meanings of Materials, PhD thesis, TU-Delft, The Netherlands.

Karana, E., Hekkert, P. and Kandachar, P. (2009) 'Meanings of materials through sensorial and manufacturing processes', Materials \& Design, Vol. 30, No. 7, pp.2778-2784, doi: 10.1016/ j.matdes.2008.09.028. 
Kawabata, S. (1982) 'The development of the objective measurement of fabric handle', in Kawabata, S., Postle, R. and Niwa, M. (Eds.): Objective Specification of Fabric Quality, Mechanical Properties and Performance, pp.31-59, Textile Machinery Society of Japan, Osaka.

Kim, H. and Winakor, G. (1996) 'Fabric hand as perceived by US and Korean males and females', Clothing and Textiles Research Journal, Vol. 14, No. 2, pp.133-144, doi: 10.1177/ $0887302 X 9601400204$.

Kooistra, K.J., Pyburn, R. and Termorshuizen, A.J. (2006) The Sustainability of Cotton: Consequences for Man and Environment, Science Shop Wageningen University \& Research Centre, Report 223, ISBN: 90-6754-90-8585-000-2.

Krippendorff, K. and Butler, R. (2008) 'Semantics: meanings and contexts of artefacts', in Schifferstein, H.N.J. and Hekkert, P. (Eds.): Product Experience, pp.353-376, Elsevier, London.

Kruskal, J.B. and Wish, M. (1978) 'Multidimensional scaling', Clothing and Textiles Research Journal, Vol. 14, No. 2, pp.133-144.

Lai, S-S., Shyr, T-W. and Lyn, J-Y. (2002) 'Comparison between KES-FB and FAST in discrimination of fabric characteristics', Journal of Textile Engineering, Vol. 48, No. 2, pp.43-48.

Laughlin, J. (1991) 'Perception of fabrics: a texturalcentric study of the visual and tactile responses of adult and elderly women', International Journal of Clothing Science and Technology, Vol. 3, No. 5, pp.20-31.

Lederman, S.J. and Klatzky, R.L. (2009) 'Haptic perception: a tutorial', Attention, Perception \& Psychophysics, Vol. 71, No. 7, pp.1439-1459.

Lee, H., Kim, J. and Fiore, A.M. (2010) 'Affective and cognitive online shopping experience', Clothing and Textiles Research Journal, Vol. 28, No. 2, pp.140-154.

Ly, N.G., Tester, D.H., Buckenham, P., Rockzniok, A.F., Adriaansen, A.L., Scaysbrook, F. et al. (1991) 'Simple instruments for quality control by finishers and tailors', Textile Research Journal, Vol. 61, No. 7, pp.402-406.

Minazio, P.G. (1995) 'FAST - fabric assurance by simple testing', International Journal of Clothing Science and Technology, Vol. 7, Nos. 2/3, pp.43-48.

Moody, W., Morgan, R., Dillon, P., Baber, C. and Wing, A. (2001) 'Factors underlying fabric perception', in Baber, C., Faint, M., Wall, S. and Wing, A.M. (Eds.): Eurohaptics 2001 Conference Proceedings, 1-4 July, pp.192-201, University of Birmingham, Birmingham, UK.

Nogueira, C., Cabeco-Silva, M.E., Schacher, L. and Adolphe, D. (2009) 'Textile materials: tactile describers', Journal of Food Technology, Vol. 7, No. 3, pp.66-70.

Orzechowski, P., Atkinson, D., Methven, T., Padilla, S., Chantler, M. and Baurley, S. (2011) 'Interactivity to enhance perception: does increased interactivity in mobile visual presentation tools facilitate more accurate rating of textile properties?', MobileHCI'11 Proceedings of the 13th International Conference on Human Computer Interaction with Mobile Devices and Services, 30 August-2 September 2011, Stockholm, Sweden, pp.629-634, ACM Press, New York.

Pan, N. (2007) 'Quantification and evaluation of human tactile sense towards fabrics', International Journal of Design and Nature, Vol. 1, No. 1, pp.48-60.

Petreca, B., Bianchi-Bertouze, N., Baurley, S., Watkins, P. and Atkinson, D. (2013) 'An embodiment perspective of affective touch behaviour in experiencing digital textiles', Proceedings ACII 2013.

Philippe, F., Schacher, L., Adolphe, D.C. and Dacremont, C. 2003. 'The sensory panel applied to textile goods - a new marketing tool', Journal of Fashion Marketing and Management, Vol. 7, No. 3, pp.235-248, doi: 10.1108/13612020310484799.

Picard, D., Dacremont, C., Valentin, D. and Giboreau, A. (2003) 'Perceptual dimensions of tactile textures’, Acta Psychologica, Vol. 114, No. 2, pp.165-184, doi: 10.1016/j.actpsy.2003.08.001.

Smith, J.E. (1986) ‘The comfort of clothing', World Textiles, Vol. 15, No. 1, pp.23-27. 
Sonneveld, M.H. and Schifferstein, H.N.J. (2008) 'The tactual experience of objects', in Schifferstein, H. and Hekkert, P. (Eds.): Product Experience, pp.41-69, Elsevier.

Soufflet, I., Calonnier, M. and Dacremont, C.A. (2004) 'Comparison between industrial experts' and novices' haptic perceptual organisation: a tool to identify descriptors of the handle of fabrics', Food Quality and Preference, Vol. 15, No. 7, pp.689-699, doi: 10.1016/ j.foodqual.2004.03.005.

Sular, V. and Okur, A. (2008) 'Handle evaluation of men's suitings produced in Turkey', Fibers and Textiles in Eastern Europe, Vol. 16, No. 2, pp.61-68.

Valatkiene, L. and Strazdiene, E. (2006) 'Accuracy and reliability of fabric's hand subjective evaluation’, Materials Science (Medziagotyra), Vol. 12, No. 3, pp.253-257.

van Kesteren, I.E.H. (2008) 'Product designers' information needs in materials selection', Materials \& Design, Vol. 29, No. 1, pp.133-145, doi: 10.1016/j.matdes.2006.11.008.

Winakor, G., Kim, C.J. and Wolins, L. (1980) 'Fabric hand: tactile sensory assessment', Textile Research Journal, Vol. 50, No. 10, pp.601-610.

Yenket, R., Chambers, E. and Gatewood, B.M. (2007) 'Color has little effect on perception of fabric handfeel tactile properties in cotton fabrics', Journal of Sensory Studies, Vol. 22, No. 3, pp.336-352. 